\title{
Collaborative Management of Complex Major Construction Projects: AnyLogic-Based Simulation Modelling
}

\author{
Na Zhao and Shi An \\ School of Management, Harbin Institute of Technology, Heilongjiang 150001, China \\ Correspondence should be addressed to Shi An; zhaona@hit.edu.cn \\ Received 9 September 2015; Revised 5 December 2015; Accepted 11 January 2016 \\ Academic Editor: Miguel Ángel López
}

Copyright ( 2016 N. Zhao and S. An. This is an open access article distributed under the Creative Commons Attribution License, which permits unrestricted use, distribution, and reproduction in any medium, provided the original work is properly cited.

Complex supply chain system collaborative management of major construction projects effectively integrates the different participants in the construction project. This paper establishes a simulation model based on AnyLogic to reveal the collaborative elements in the complex supply chain management system and the modes of action as well as the transmission problems of the intent information. Thus it is promoting the participants to become an organism with coordinated development and coevolution. This study can help improve the efficiency and management of the complex system of major construction projects.

\section{Introduction}

Major constructions are surged unimaginably in demand along with the development of science, technology, and society. According to Morgan Stanley research report, the emerging economies are expected to spend $\$ 21.7$ trillion for major infrastructure projects between 2009 and 2019. Like most countries, the Chinese government will spend $\$ 9$ trillion which is the $12 \%$ of GDP on the major constructions [1]. However, the major constructions often have some urgent problems in the collaborative management field and suffer many problems and shortcomings from the traditional mode of project management, for example, the project cost exceeding budgets, the project duration delays, and the owners' dissatisfaction.

Some basic characteristics of modern major construction projects are long construction period, large investment, and complex organization relationship. Although there is no linearly proportional relationship between scale and complexity, high construction cost is a common characteristic of complex major construction projects. In general, the more complex major construction projects have both a longer construction period and a higher cost [2]. At the same time, the fields involved in major construction projects are increasing, such as transportation, real estate, and medical fields. It leads to the major construction project which involves more organizations. Therefore, the major construction projects need to organize the organizations and people with different functions and experiences, which further increase the organizational complexity.

In modern major construction projects, the external characteristics of culture and environment are stronger uncertainty and turbulence. The unforeseeable factors in the implementation process of major construction projects have increased. Not only are projects affected by the local governments and the social, economic, and cultural environments, but they are restricted by local resources, climate, and geology. In particular, multiple participants of major construction projects, such as the owner, consulting party, designer, contractors, suppliers, and operators, have different social psychologies, cultures, habits, and specialties, which increases the difficulty in communication [3,4]. In addition, with the intensifying international competition in major construction projects and the increasingly internationally cooperated major construction projects, participants are often from different countries. It is because most of the major constructions of the tender are globally oriented. They seek the most suitable contractor in the world. For example, throughout the world, many countries are actively striving for high-speed rail 
projects. Some factors increase the risks of major construction projects. Major projects have different social systems, cultures, and legal backgrounds and are in different languages, which increase barriers to communication and the complexity of project management. The increasing environmental uncertainty is the main source leading to the complexity of major construction project [5].

Based on the above analysis, the traditional process of major construction projects is needed to innovate and consolidate the management. It is difficult for traditional major construction projects to use a production process similar to that of other industries. The owners cannot obtain complete building products and perfect service. They have no ability to manage major construction projects but have to participate in the construction process. They must perform complex management work and bear the resulting responsibility, leading to many entanglements [6]. In addition, due to the specialty limitation of major construction projects, it has different spanning periods or implementation parities. So it is hard to coordinate between a superior and an inferior, and this leads to discontinuity of management at last.

Major construction projects have their own general objectives and requirements, but due to the different organization tasks and persons responsible in different phases, the tasks are undertaken by different enterprises, resulting in the separation of project organization, inconsistent objectives, and discrete responsibilities. Due to the inconsistent objectives among the participants, they balance each other, leading to tense relationships and low working efficiency, which inhibits enthusiasm and creativity. Significant costs, time, and energy are spent on various working interfaces [7]. Because the interests of the participants of a project have nothing to do with its ultimate benefit, people's short-term actions are more serious than those in other organizations, which easily produce the ideal for all construction. The participants pay attention to the short-term local interests and ignore the operation status of the project and the requirement of continuous development, thus failing to realize the general optimization of the life cycle of a major construction project. Moreover, there are obvious blind areas in the organizational responsibility system, which increases the risks for all participants. For example, governments and manufacturers must use positive political connections to achieve product protection and supervision of safety throughout the supply chain [8], and the agent's working efficiency is decreased, which may erode the value of the company [9].

The long construction period, large investment, complex organizational relationship, uncertain cultural environment, and breaking in phase of major construction projects are objective problems that are difficult to solve. However, complex objective and information isolation can be improved through management. The traditional management system, managing mode and idea of major construction projects, cannot satisfy and adapt to the needs of complex key project management [10]. The complexity of a major construction project raises new requirements on management. Thus, it has important theoretical and realistic significance in the research of the collaboration of the complex system of major construction projects [11].

\section{Literature Review}

The following subsections are talking about collaborative management of complex major construction projects which are based on AnyLogic. The research subject is a complex system of major construction project. The research perspectives of collaborative management are from the relationship among the participants, through mathematical analysis, adopting the research methods of simulation modelling. In this paper, the existing research as theoretical basis stands in a new perspective to discuss the coordinated management of major constructions.

2.1. Complex Supply Chain of Major Construction Projects. A major construction project supply chain is called CPSC. The simulation models are applied to study a specific coordination mechanism where coordination requirements are produced in different departments with complex relationships in key organizations. In addition, it is considered that the VDT (Virtual Design Team) model is more suitable for research of projects with unpredictable factors. It is a formal method for developing the new microlevel behavioral mechanisms as the primary point of departure from the aspect of information processing. And the microcontingency model generates a set of testable hypotheses related to these theorized microlevel behaviors [12]. Mihm et al. studied the impact of the hierarchical organizational structure on the speed of the searching decision-making plan and the stability and quality of the problem solutions by combining mathematical analysis and simulation models [13]. Cope et al. pointed out that NASA faced the difficulty of how to effectively manage and coordinate the experts in different places and proposed to design a case study where the approach was implemented to model, simulate, and analyse NASA's Space Exploration Supply Chain [14].

\subsection{Collaborative Management of Major Construction} Projects. For the relationship among the participants, Ruff et al. noted that, due to the greater uncertainty of major construction projects, it is easier to cause discordance among the participants, leading to project delays, cost exceeding, and disputes. The authors analysed the relationship among the participants of those projects and presented the problems to address in project management [15]. Hinze and Tracey studied the relationship between principal contractors and subcontractors from the perspective of the subcontractor and noted that some behaviour of principal contractors may cause harm to the industry [16]. Cheung analysed the key factors of the Alternative Dispute Resolution (ADR) method for solving disputes with the analytic hierarchy process and noted that the disputes would be solved more efficiently using the ADR method if attention was paid to those key factors [17]. Bond and Naus studied the communication issue of engineering projects and put forward six factors affecting the communication efficiency of project participants and a way to improve communication [18]. Therefore, the collaborative management of major construction projects has important significance. Appropriate application of collaborative management can improve the flexibility in the physical 
distribution and minimize the inefficiency of major construction projects $[19,20]$.

\subsection{Supply Chain Simulation Management Based on System} Dynamics. The application of system dynamics to supply chain management can be traced back to 1958. Senge and Forrester used system dynamics to solve some operation and management problems in industry, such as demand amplification, stock volatility, instability between production and employees, influence of advertising strategies on production change, and impact of information technology on management [21]. The earliest application of system dynamics in the supply chain was the research on the bullwhip effect. Towill et al. studied the changing range of demand information with the supply chain using system dynamics and found that the demand information was doubled at each link and amplified eightfold when the manufacturers received orders from the distributors [22]. Anderson and Morrice took the machine tool industry as an example to explore the content of demand amplification of the machine tool supply chain in the lead time, inventory, productivity, and human with system dynamics, tested several strategies for improving the performance of the supply chain, and created simulations with the statistical fitting data [23]. The results showed that market volatility and investment acceleration led to improvement of the production capacity and significant amplification of demand. The flexible order strategy and employment strategy could help overcome demand amplification and improve the operation of the entire supply chain [24].

Given all that, major construction projects are a complex adaptive system with complexity as an important feature. So far, few studies specifically consider the impact of complexity on major construction projects because major construction projects can be neither copied nor repeated. In addition, the local complex environment cannot be copied. Therefore, a simulation modelling method based on the principle of system dynamics can simulate the complex situation in the complex supply chain system of major construction projects, which is conducive to the research of the collaborative management of the complex supply chain system of major construction projects [25].

\section{Modelling}

This paper classifies the population into the following 4 types: Potential Recipient of informative intention $P$, recipient of informative intention $R$, recipient of delivering informative intention, and forgetter of informative intention $F$; then the research sets up a complex system information delivering model TRANSFER as follows:

$$
\begin{aligned}
& \frac{d P(t)}{d t}=-\beta g(D(t)) P(t)+\nu-\nu P(t)+\delta F(t), \\
& \frac{d R(t)}{d t}=\beta g(D(t)) P(t)-(\varepsilon+\nu) R(t),
\end{aligned}
$$

$$
\begin{aligned}
& \frac{d D(t)}{d t}=\varepsilon R(t)-(\gamma+\nu) D(t), \\
& \frac{d F(t)}{d t}=\gamma D(t)-(\delta+\nu) F(t) .
\end{aligned}
$$

When $g(0)=0, g \in C 1(0,1)$, and $D \in(0,1), g(D)>0$. If $\delta \rightarrow 0$ or $\varepsilon \rightarrow \infty$, model (1) can be simplified into a complex system information delivering model. The complex system supply chain that collaborated with the equilibrium point of model (1) can be overall asymptotically stable when $\delta$ is sufficiently small or $\varepsilon$ is sufficiently large. Considering the relative factors during information delivery, this paper establishes the following general nonlinear function of the TRANSFER complex system information delivering model (2).

In the complex SCM of critical engineering, the number of participants is dynamic. Some people pull out of the construction link once they finish a certain portion, and a new craft takes their place and continues construction.

The proficiency and work duration of each participant differ; hence, the paper presumes that $e(t, \tau)$ represents the number of potential recipients of informative intention at time $t$ on the condition of $\tau$ working years, where $\varepsilon(\tau)$ and $\beta(\tau)$ are, respectively, working year $\tau$ 's receiving rate and the delivering rate of potential recipients of informative intention, $\Lambda, \mu, \alpha, \delta, \gamma$ are critical engineering participants' increasing and decreasing coefficients, $\mu$ is the natural failure rate of information, $\alpha$ is failure rate of information, $\delta$ is the success rate of delivering information, and $C(P, R, D, F)$ is the delivering rate. Then, $[C(P(t), R(t), D(t), F(t)) / N(t)]$. $P(t) \int_{0}^{\infty} \beta(\tau) e(t, \tau) d \tau$ are the new recipients at the time of $t$ in different stages of working years, as well as the number of secluded recipients at time $t[\sigma(P(t), R(t), D(t), F(t)) / N(t)]$. $\int_{0}^{\infty} e(t, \tau) d \tau$. Consider

$$
\begin{aligned}
& N(t)=P(t)+R(t)+D(t)+F(t), \\
& e(t, o)=\frac{C(P(t), R(t), D(t), F(t))}{N(t)} P(t) \\
& \quad \cdot \int_{0}^{\infty} \beta(\tau) e(t, \tau) d \tau, \\
& P(0)=P_{0}, \\
& e(0, \tau)=\eta(\tau), \\
& D(0)=D_{0}, \\
& F(0)=F_{0} .
\end{aligned}
$$

By applying fixed point theory and the continuation theorem of the solution, this research can prove the existence of a global nonnegative solution. This paper emphasizes the existence and stability of critical engineering complex SCM that collaborated with the equilibrium point. Therefore, the research develops the following fundamental assumption for its parameters: $\sigma, C$ are nonnegative continuous differentiable functions of $R^{4}$, and $\partial C / \partial P, \partial C / \partial R, \partial C / \partial D, \partial C / \partial F, \partial \sigma / \partial P$, $\partial \sigma / \partial R, \partial \sigma / \partial D, \partial \sigma / \partial F \in L^{\infty}([0, \infty) \times[0, \infty) \times[0, \infty) \times[0, \infty))$ 
that nonnegative functions $\varepsilon$ and $\beta$ meet the condition $\varepsilon(\cdot) \in$ $C^{1}[0, \infty) \cap L^{\infty}[0, \infty), \varepsilon^{\prime}(\cdot) \in L^{\infty}[0, \infty), \beta(\cdot) \in C^{2}[0, \infty) \cap$ $L^{\infty}[0, \infty)$, as well as $\beta^{\prime}(\cdot), \beta^{\prime \prime}(\cdot) \in L^{\infty}[0, \infty) . \Lambda, \mu, \alpha, \gamma, \delta$ are positive constants recorded as $\|\cdot\|_{1}$ and $\|\cdot\|_{\infty}$. These two constants are, respectively, the Banach space's $L^{1}[0, \infty)$ and $L^{\infty}[0, \infty)$ norms. If the paper records $L_{+}^{1}[0, \infty)$ as the positive cone of Banach space $L^{1}[0, \infty), \eta(\cdot) \in L_{+}^{1}[0, \infty)$.

3.1. Asymptotic Stability of the Equilibrium Point. The equilibrium point of the complex SCM information delivering model represents the final condition of information delivering and coordination. The stability decides the ability of information delivering for the final condition. Next, the paper studies the existence and stability of model (2)'s equilibrium point. If it assumes $\left(P^{*}, e^{*}(\tau), D^{*}, F^{*}\right)$ as system's equilibrium point, it is necessary and sufficient that condition of existence should satisfy the following integrodifferential equations:

$$
\begin{aligned}
& \Lambda-\mu P^{*}-B^{*}+\delta B^{*}=0, \\
& \frac{d e^{*}(\tau)}{d \tau} \\
& \quad=-(\mu+\varepsilon(t)) e^{*}(\tau)-\frac{\sigma\left(P^{*}, R^{*}, D^{*}, F^{*}\right)}{N^{*}} e^{*}(\tau), \\
& \int_{0}^{\infty} \varepsilon(\tau) e^{*}(\tau) d-m D^{*}=0, \\
& \gamma D^{*}-n F^{*}+\frac{\sigma\left(P^{*}, R^{*}, D^{*}, F^{*}\right)}{N^{*}} E^{*}=0, \\
& B^{*}=\frac{C\left(P^{*}, R^{*}, D^{*}, F^{*}\right)}{N^{*}} P^{*} \int_{0}^{\infty} \beta(\tau) e^{*}(\tau) d \tau,
\end{aligned}
$$

from which we can conclude that $R^{*}=\int_{0}^{\infty} e^{*}(\tau) d \tau, N^{*}=$ $P^{*}+R^{*}+D^{*}+F^{*}, m=\mu+\alpha+\gamma$, and $n=\mu+\delta$, and the system always contains the unique null information equilibrium point $(\Lambda / \mu, 0,0,0)$. Then, the paper discusses the existence of the complex system SCM that collaborated with the equilibrium point. Consider

$$
\begin{aligned}
M(t) & =\frac{C(P(t), R(t), D(t), F(t)) P(t)}{N(t)}, \\
M^{*} & =\frac{C\left(P^{*}, R^{*}, D^{*}, F^{*}\right) P^{*}}{N^{*}}, \\
M_{1}^{*} & =\frac{\partial M\left(P^{*}, R^{*}, D^{*}, F^{*}\right)}{\partial P^{*}}, \\
M_{2}^{*} & =\frac{\partial M\left(P^{*}, R^{*}, D^{*}, F^{*}\right)}{\partial R^{*}}, \\
M_{3}^{*} & =\frac{\partial M\left(P^{*}, R^{*}, D^{*}, F^{*}\right)}{\partial D^{*}}, \\
M_{4}^{*} & =\frac{\partial M\left(P^{*}, R^{*}, D^{*}, F^{*}\right)}{\partial F^{*}} \\
a(\cdot) & =\mu+\varepsilon(\cdot)+\frac{\sigma\left(P^{*}, R^{*}, D^{*}, F^{*}\right)}{N^{*}}
\end{aligned}
$$

$$
\begin{aligned}
N^{*} & =P^{*}+R^{*}+D^{*}+F^{*}, \\
e^{*}(\tau) & =B^{*} \pi_{a}(\tau) .
\end{aligned}
$$

The research obtains (4) from the second equation; then plug (4) into (3):

$$
\begin{aligned}
& P^{*}=\frac{\left(\Lambda-B^{*}+\delta F^{*}\right)}{\mu}, \\
& R^{*}=B^{*} \int_{0}^{\infty} \pi_{a}(\tau) d \tau, \\
& D^{*}=\frac{B^{*}}{m} \int_{0}^{\infty} \varepsilon(\tau) \pi_{a}(\tau) d \tau, \\
& F^{*}=\frac{\gamma}{n} D^{*}+\frac{Q^{*}}{n} R^{*}, \\
& B^{*}=M^{*} B^{*} \int_{0}^{\infty} \beta(\tau) \pi_{a}(\tau) d \tau .
\end{aligned}
$$

From (5), we can regard $P^{*}, R^{*}, D^{*}, F^{*}$ as $B^{*}$ 's continuous function and record it as $P\left(B^{*}\right)=P^{*}, R\left(B^{*}\right)=R^{*}, D\left(B^{*}\right)=$ $D^{*}$, and $F\left(B^{*}\right)=F^{*}$, and then define it as follows:

$$
G\left(B^{*}\right)=\frac{C\left(P^{*}, R^{*}, D^{*}, F^{*}\right)}{N^{*}} P^{*} \int_{0}^{\infty} \beta(\tau) \pi_{a}(\tau) d \tau .
$$

Then, $G$ will still be $B^{*}$ 's continuous function. If the design sets $\mathfrak{R}_{0}=C(\Lambda / \mu, 0,0$, 0) $\int_{0}^{\infty} \beta(\tau) e^{-\int_{0}^{\tau}(\mu+\varepsilon(s)+\mu \sigma(\Lambda / \mu, 0,0,0) / \Lambda) d s} d \tau$, it can conclude the following.

Theorem 1. When $\mathfrak{R}_{0}>1$, the system will have at least one complex system SCM equilibrium point; when $\mathfrak{R}_{0} \leq 1$ and $G$ strictly decreases monotonically, the system will no longer have an equilibrium point. $G$ is defined by formula (6).

From (5), the necessary condition of existence of a positive equilibrium is a positive number $B^{*}$, which makes the fourth equation's validity of formula (5). The necessary and sufficient condition of $B^{*}$ as the fourth solution of formula (5) is $G\left(B^{*}\right)=1$.

When $B^{*}$ is sufficiently large, $G\left(B^{*}\right)<0$. Because $G(0)=$ $\mathfrak{R}_{0}$, there exists at least one positive number $B^{*}$ that makes $G\left(B^{*}\right)=1$ valid when $\mathfrak{R}_{0}>1$. Then, the system will have at least one positive equilibrium point based on formula (5).

When $\mathfrak{R}_{0}<1$ (namely, $G(0) \leq 1$ ) and $G$ is a strictly decreasing function, if $\forall B^{*}>0, G\left(B^{*}\right)<1$. Then, the system will have a null information coordination equilibrium point.

Next, in order to study the stability of equilibrium point (2). At first, the research need to discuss the global asymptotic stability of the null information coordination equilibrium point when $\Re_{0}<1$.

Theorem 2. Assume $C(P, R, D, F)=C(N), \sigma(P, R, D, F)=$ $\sigma(N)$, and $C^{\prime}(N) \geq 0,(\sigma(N) / N)^{\prime} \leq 0$. Then, system's null information equilibrium point will have global asymptotic stability if $\Re_{0}<1$. 
Theorem 3. If $\Re \geq 1$, random nonnegative numbers $P, R, D$, F,

$$
\begin{aligned}
& C(P, R, D, F) \leq C\left(\frac{\Lambda}{\mu}, 0,0,0\right), \\
& \sigma(P, R, D, F) \geq \sigma\left(\frac{\Lambda}{\mu}, 0,0,0\right),
\end{aligned}
$$

can meet the system's null information equilibrium point which will have global asymptotic stability. Then, examining the stability $\left(P^{*}, e^{*}(\tau), D^{*}, F^{*}\right)$, the critical engineering complex information synergy balance. If the research assumes $\bar{X}(t)=$ $(\bar{P}(t), \bar{R}(t), \bar{D}(t), \bar{F}(t), \bar{B}(t))^{T}$, the $\bar{X}(t)$ will satisfy the following equation:

$$
A \bar{X}(t)=\int_{0}^{t} K(t-\tau) \bar{X}(\tau) d \tau=f(t) .
$$

It can then be proved that positive number $H$ makes $K$ and its derivative satisfy

$$
\|K(t)\|,\|\dot{K}(t)\|\|\ddot{K}(t)\| \leq H s^{-\mu t} .
$$

Analysing $K(t)$ 's Laplace conversion $\widehat{K}(s)$ in the right half plane $\operatorname{Re}(s)>-\mu$ of the complex plane and on the condition that $\lim _{|s| \rightarrow \infty} \widehat{K}(s)=0$, conclude $\lim _{|s| \rightarrow \infty} \operatorname{det}(A+\widehat{K}(s))=1$. Therefore, all roots of $\operatorname{det}(A+\widehat{K}(s))$ are isolated in the circle centred at the origin. If the design sets all roots of $\operatorname{det}(A+$ $\widehat{K}(s))$ as having a negative real part, there will exist $\mu^{*}, 0<$ $\mu^{*}<\mu$, that makes all roots in $\operatorname{Re}(s)<-\mu^{*}$. When it sets $L(s)$ as $A+\widehat{K}(s)$ 's analytic inverse in $\operatorname{Re}(s) \geq-\mu^{*}$ because $A$ is reversible and $\lim _{|s| \rightarrow \infty} \widehat{K}(s)=0$ for sufficiently large $|s|$, on the condition that $\operatorname{Re}(s)>-\mu$, the following can be obtained:

$$
\begin{aligned}
L(s) & =A^{-1}\left(I+A^{-1} \widehat{K}(s)\right)^{-1} \\
& =A^{-1} \sum_{j=0}^{\infty}\left(A^{-1} \widehat{K}(s)\right)^{j},
\end{aligned}
$$

$$
\lim _{|s| \rightarrow \infty} L(s)=\lim _{|s| \rightarrow \infty} A^{-1}\left(I+A^{-1} \widehat{K}(s)\right)^{-1}=A^{-1} .
$$

By applying Taylor's formula, it can be concluded that $\widehat{K}(s)=K(0) / s+K(0) / s^{2}+o\left(s^{-2}\right)$ on the condition that $s \in$ $\left\{s \in C \mid \operatorname{Re}(s) \geq-\mu^{*}\right\},|s| \rightarrow \infty$. Therefore, when $s \in\{s \in$ $\left.C \mid \operatorname{Re}(s) \geq-\mu^{*}\right\},|s| \rightarrow \infty$, there exists a constant matrix $J_{0}$ that makes $L(s)=A^{-1}+J_{0} / s+o\left(s^{-2}\right)$. These results indicate that $\widehat{J}(s)=L(s)-A^{-1}$ is $J(t)$ 's Laplace conversion, and $J(t)=$ $(1 / 2 \pi) e^{-\mu^{*} t} \int_{-\infty}^{\infty} e^{i \xi t} \widehat{J}\left(-\mu^{*}+i \xi\right) d \xi, t \geq 0$.

Because $i$ is an imaginary unit, by formula (9) there exists a positive number $H_{1}$ that makes $\|J(t)\| \leq H_{1} e^{-\mu^{*} t}, t \geq 0$. To investigate the asymptotic stability of the positive equilibrium point, assume the following:

(i) $\left|M(t)-M^{*}-\nabla M^{*} \cdot(\bar{P}(t), \bar{R}(t), \bar{D}(t), \bar{F}(t))\right|=o(|\bar{P}(t)|+$ $|\bar{R}(t)|+|\bar{D}(t)|+|\bar{F}(t)|)$. When $|\bar{P}(t)|+|\bar{R}(t)|+|\bar{D}(t)|+|\bar{F}(t)| \rightarrow$ 0 , namely, $\forall \epsilon_{0}>0, \exists \bar{\delta}\left(\varepsilon_{0}\right)>0$, which makes $|\bar{P}(t)|+|\bar{R}(t)|+$ $|\bar{D}(t)|+|\bar{F}(t)|<\bar{\delta}\left(\varepsilon_{0}\right), \mid M(t)-M^{*}-\nabla M^{*} \cdot(\bar{P}(t), \bar{E}(t), \bar{R}(t)$, $\bar{F}(t)) \mid<\varepsilon_{0}(|\bar{P}(t)|,|\bar{E}(t)|,|\bar{R}(t)|,|\bar{F}(t)|)$. (ii) $\left|Q(t)-Q^{*}-\nabla Q^{*} \cdot(\bar{P}(t), \bar{R}(t), \bar{D}(t), \bar{F}(t))\right|=o(|\bar{P}(t)|+$ $|\bar{R}(t)|+|\bar{D}(t)|+|\bar{F}(t)|)$.

When $|\bar{P}(t)|+|\bar{R}(t)|+|\bar{D}(t)|+|\bar{F}(t)| \rightarrow 0$ (namely, $\forall \epsilon_{0}>0, \exists \delta\left(\varepsilon_{0}\right)>0$, which makes $|\bar{P}(t)|+|\bar{R}(t)|+|\bar{D}(t)|+$ $\left.|\bar{F}(t)|<\bar{\delta}\left(\varepsilon_{0}\right)\right),\left|Q(t)-Q^{*}-\nabla Q^{*} \cdot(\bar{P}(t), \bar{R}(t), \bar{D}(t), \bar{F}(t))\right|<$ $\varepsilon_{0}(|\bar{P}(t)|,|\bar{R}(t)|,|\bar{D}(t)|,|\bar{F}(t)|)$.

When $\sigma(P(t), R(t), D(t), F(t))=\beta_{1} N(t), C(P(t), R(t)$, $D(t), F(t))=\beta_{2} N(t)$; the above assumption is naturally available, among which $\beta_{1}, \beta_{2}$ are positive numbers and $N(t)$ is the population size.

\section{Simulation}

The complex supply chain of a major construction project refers to the construction process from the preliminary work, including the definition of the project, feasibility research and design, key project implementation, completion, acceptance, and maintenance, to all activities in the processes of expansion and building demolition as well as all organizational institutions involved. The complex system of a major construction project is an overall functional mode that combines owners, consultants, designers, construction parties, and material and equipment suppliers into a whole through the control of information flow, logistics, and cash flow, in which the owners are the investor, supplier, and final user as well, and other node enterprises are driven by the demand information to realize the value of the whole supply chain through the division of labour and cooperation.

Because there are many participants in the complex system of major construction projects, collaboration consistency is bound to undergo severe tests in the overall operation. Thus, the root cause of difficult collaboration is that different participants have different objectives, and the information transmission is obstructed. This paper presents a model that shows the transmission of the informative intention in the process of key project construction and seeks the key time points for collaborative consistency to strengthen the collaborative management of the complex system of major construction projects.

So, this paper builds a model that constructed a visual simulation model. Figure 1 is this paper elaboration, and it shows the process of the informative intention in the key project construction intuitively. It indicates a simulation model which is based on the above model of mathematical building and analysis. And then, the second part of Figure 1 shows the application of this simulation model.

4.1. Role Characteristics of Four Important Characters in the Complex System of Major Construction Projects. As shown in Figure 1, participants are divided into four categories according to their respective stage characteristic which is from the intention information transmission of the major construction projects. They are specifically as follows:

(i) Potential Recipient (potential intent information receiver): people who do not receive the intent information. 


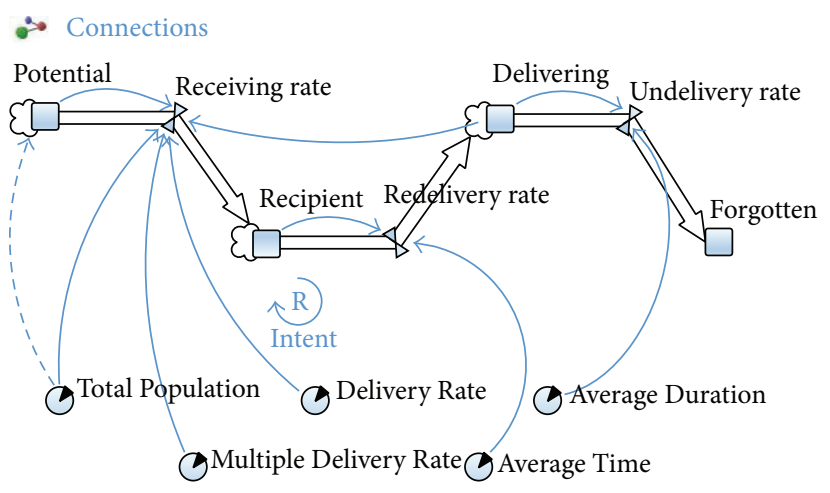

(a)

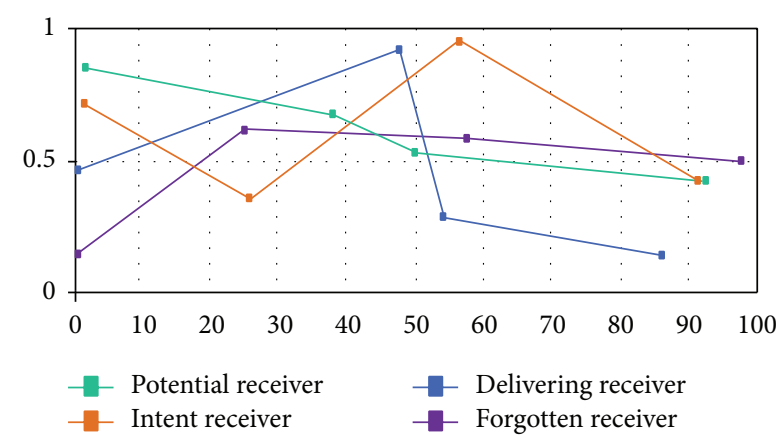

(b)

FIGURE 1: The information simulation model of collaborative management.

(ii) Intent Recipient (receiver who has received the intent information): people who have received the intent information but have not transmitted to others.

(iii) Delivering Recipient (receiver in the process of intent information transmission): people who have received the information and transmitted it to other potential intent information receivers.

(iv) Forgotten Recipient (people who have received the intent information but then forgotten it) [26].

4.2. Defining Parameters and Subordinates. The parameters and subordinates are defined as follows:

(i) Participants. Considering a model of a key project with 10000 participants, first, the leader has intent information concerning the key project to be transmitted and other people become the potential intent information receivers.

(ii) Delivery Rate. In the initial stage of key project construction, each person transmits the information to others at the transmission and reception rate of 1.25.

(iii) Multiple Delivery Rate. If the receiver who has received the information meets other receivers who may have received the information, the transmission rate of the intent information by the latter is Multiple Delivery Rate.

(iv) Average Time. When a person receives information, there is a thinking period that lasts 10 days. In this stage, the information receiver becomes familiar with the information.

(v) Average Duration. After the thinking period, the intent information will last for a time period in the consciousness of the information receiver. The average lasting time of the information is 15 days.

(vi) Information receivers who have forgotten the intent information will not participate in the retransmission of the information.
Figures and Tables. The paper hypothesizes and defines related index (Table 1). The details are as follows:

(i) Total Population $=10000$.

(ii) Delivery Rate $=1.25$.

(iii) Multiple Delivery Rate $=0.6$.

(iv) Average Time $=10$.

(v) Average Duration $=1$.

4.3. Analogy Simulation. The research performs simulation modelling of the complex supply chain coordinative management process of critical engineering by adopting the simulation software AnyLogic. Figure 1 depicts the system information synergy for the complex system of major construction projects. It shows the transmission of the informative intention in the process of key project construction and seeks the key time points for collaborative consistency to strengthen the collaborative management of the complex supply chain of major construction projects. The result of the simulation model indicates that, based on the TRANSFER model's adjustment applied to the system, it can not only observe the macroscopic operational process of the whole supply chain coordinative management but also measure certain links of the system microscopically.

The Application. The model can observe 4 kinds of different participants visually (Potential Recipient, Intent Recipient, Delivering Recipient, and Forgotten Recipient). It is helpful to understand the structure and dynamics of the intention information transmission in the major construction which was a complex system. And it can help the organization take the appropriate strategy in the process of major constructions management.

\section{Conclusions}

This paper conducts innovation research on the complex system coordinative management of critical engineering and develops a mathematical model. The mathematical analytical 
TABLE 1: Inflows and outflows.

\begin{tabular}{lcc}
\hline Stock & Inflows & Outflows \\
\hline $\begin{array}{l}\text { Total } \\
\text { Population }\end{array}$ & Potential & Receiving Rate $=$ Delivering $\times$ Delivery Rate $\times$ Multiple Delivery Rate $\times$ Potential/Total Population + Delivery Rate \\
\hline $\begin{array}{l}\text { Delivery Rate } \\
\text { Multiple }\end{array}$ & Recipient & Redelivery Rate $=$ Recipient/Average Time \\
Delivery Rate & Delivering & Undelivery Rate $=$ Delivering/Average Duration \\
\hline
\end{tabular}

part proves the existence and stability of complex system coordinated with the equilibrium point. Then, the simulation modelling of the complex coordinative management process of critical engineering is performed by adopting the simulation software AnyLogic. The result of the simulation model indicates that, based on the TRANSFER model's adjustment applied to the system, it can not only observe the macroscopic operational process of the whole supply chain coordinative management but also measure certain links of the system microscopically. This study effectively integrates the participants of different critical engineering and it explicates synergy elements and modes of action. The study further proposes the informative intention's delivering problems in the complex supply chain of critical engineering and prompts the participants of the supply chain to act as an organism of harmonious development and coevolution. This paper is beneficial to increasing the efficiency of the critical engineering complex supply chain to reform its management status.

\section{Conflict of Interests}

The authors declare that there is no conflict of interests regarding the publication of this paper.

\section{Acknowledgments}

This work was supported by the National Natural Science Foundation of China (Grant no. 71390522), China Postdoctoral Science Foundation, and Hei Long Jiang Postdoctoral Foundation of China.

\section{References}

[1] Building BRICs of growth, The Economist, June 2008, http:// www.economist.com/node/11488749.

[2] P. E. D. Love and Z. Irani, "A project management quality cost information system for the construction industry," Information \& Management, vol. 40, no. 7, pp. 649-661, 2003.

[3] J. Uher, “Conceiving 'personality': psychologist's challenges and basic fundamentals of the transdisciplinary philosophy-ofscience paradigm for research on individuals," Integrative Psychological \& Behavioral Science, vol. 49, no. 3, pp. 398-458, 2015.

[4] Z. Chen, N. Takeuchi, and M. Wakabayashi, "Managerial skill utilization: work environment, gender, and training incentive," International Journal of Human Resource Management, vol. 16, no. 5, pp. 786-808, 2005.

[5] S. Dougherty, S. Russo, and D. Freeman, "A successful strategy for environmental permitting of an aggressively scheduled major water supply project," in Proceedings of the Pipelines
Conference, pp. 1338-1349, American Society of Civil Engineers, Keystone, Colo, USA, August-September 2010.

[6] A. Walker and R. Newcombe, "The positive use of power on a major construction project," Construction Management and Economics, vol. 18, no. 1, pp. 37-44, 2000.

[7] Á. Pérez, S. Quintanilla, P. Lino, and V. Valls, "A multi-objective approach for a project scheduling problem with due dates and temporal constraints infeasibilities," International Journal of Production Research, vol. 52, no. 13, pp. 3950-3965, 2014.

[8] Z. Na and W. Fusheng, "The game analysis of manufacturers' political connections on product safety in supply Chain: evidence from China," Discrete Dynamics in Nature and Society, vol. 2013, Article ID 695384, 5 pages, 2013.

[9] N. Zhao, F. Wang, and Q. Tang, "Game analysis on the motivations for political connections in China's listed companies based on a principal-agent model," Journal of Computational Information Systems, vol. 9, no. 10, pp. 4155-4162, 2013.

[10] G.-C. Li, L.-Y. Ding, and J.-T. Wang, "Construction project control in virtual reality: a case study," Journal of Applied Sciences, vol. 6, no. 13, pp. 2724-2732, 2006.

[11] W. Smew, P. Young, and J. Geraghty, "Supply chain analysis using simulation, gaussian process modelling and optimisation," International Journal of Simulation Modelling, vol. 12, no. 3, pp. 178-189, 2013.

[12] M. Boile and L. Sdoukopoulos, "Supply chain visibility and security-the SMART-CM project solution," International Journal of Shipping and Transport Logistics, vol. 6, no. 3, pp. 280-292, 2014.

[13] J. Mihm, C. H. Loch, D. Wilkinson, and B. A. Huberman, "Hierarchical structure and search in complex organizations," Management Science, vol. 56, no. 5, pp. 831-848, 2010.

[14] D. Cope, M. S. Fayez, M. Mollaghasemi, and A. Kaylani, "Supply chain simulation modeling made easy: an innovative approach," in Proceedings of the Winter Simulation Conference (WSC '07), pp. 1887-1896, IEEE, Washington, DC, USA, December 2007.

[15] C. M. Ruff, D. A. Dzombak, and C. T. Hendrickson, "Ownercontractor relationships on contaminated site remediation projects," Journal of Construction Engineering and Management, vol. 122, no. 4, pp. 348-353, 1996.

[16] J. Hinze and A. Tracey, "The Contractor-subcontractor relationship: the subcontractor's view," Journal of Construction Engineering and Management, vol. 120, no. 2, pp. 274-287, 1994.

[17] S. Cheung, "Critical factors affecting the use of alternative dispute resolution processes in construction," International Journal of Project Management, vol. 17, no. 3, pp. 189-194, 1999.

[18] S. R. Bond and C. C. Naus, "Rf-cloning.org: an online tool for the design of restriction-free cloning projects," Nucleic Acids Research, vol. 40, no. 1, pp. W209-W213, 2012.

[19] X. Xue, Q. Shen, and Z. Ren, "Critical review of collaborative working in construction projects: business environment and human behaviors," Journal of Management in Engineering, vol. 26, no. 4, pp. 196-208, 2010. 
[20] F. T. S. Chan and T. Zhang, "The impact of collaborative transportation management on supply chain performance: a simulation approach," Expert Systems with Applications, vol. 38, no. 3, pp. 2319-2329, 2011.

[21] P. M. Senge and N. B. Forrester, Organizational Growth and Management Overhead, System Dynamics Group, Sloan School of Management, Massachusetts Institute of Technology, Cambridge, Mass, USA, 1987.

[22] D. R. Towill, M. M. Naim, and J. Wikner, "Industrial dynamics simulation models in the design of supply chains," International Journal of Physical Distribution and Logistics Management, vol. 22, no. 5, pp. 3-13, 1996.

[23] E. G. Anderson Jr. and D. J. Morrice, "A simulation game for teaching service-oriented supply chain management: does information sharing help managers with service capacity decisions," Production and Operations Management, vol. 9, no. 1, pp. 40-55, 2000.

[24] J. P. C. Kleijnen, "Supply chain simulation tools and techniques: a survey," International Journal of Simulation \& Process Modelling, vol. 1, no. 1-2, 2005.

[25] D. J. Van Der Zee and J. G. A. J. Van Der Vorst, "A modeling framework for supply chain simulation: opportunities for improved decision making," Decision Sciences, vol. 36, no. 1, pp. 65-95, 2005.

[26] H. L. Lee, V. Padmanabhan, and S. Whang, "Information distortion in a supply chain: the bullwhip effect," Management Science, vol. 43, no. 4, pp. 546-558, 1997. 


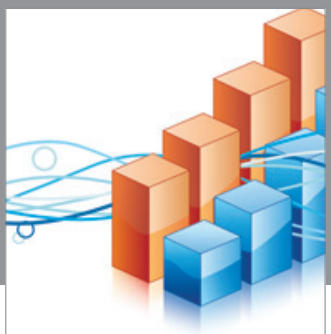

Advances in

Operations Research

vatem alat4

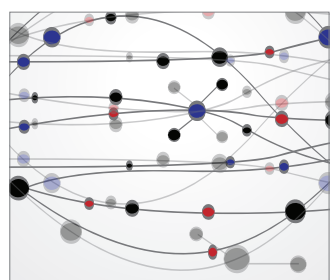

\section{The Scientific} World Journal
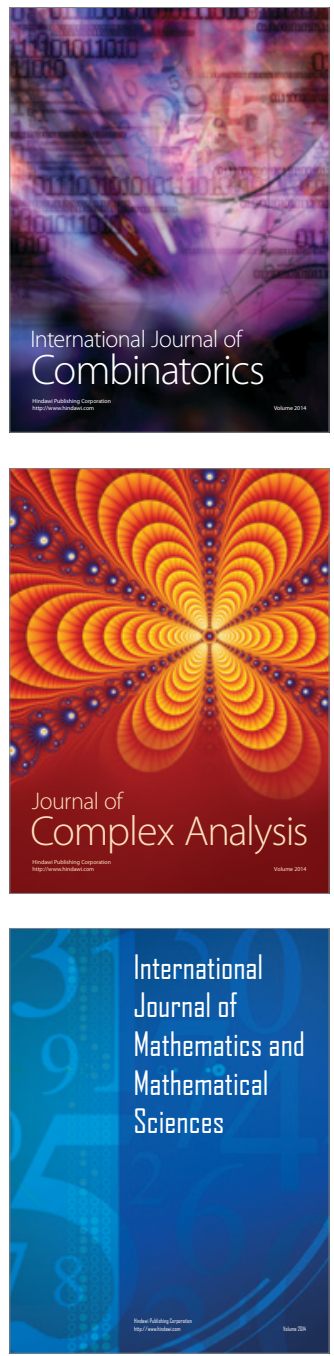
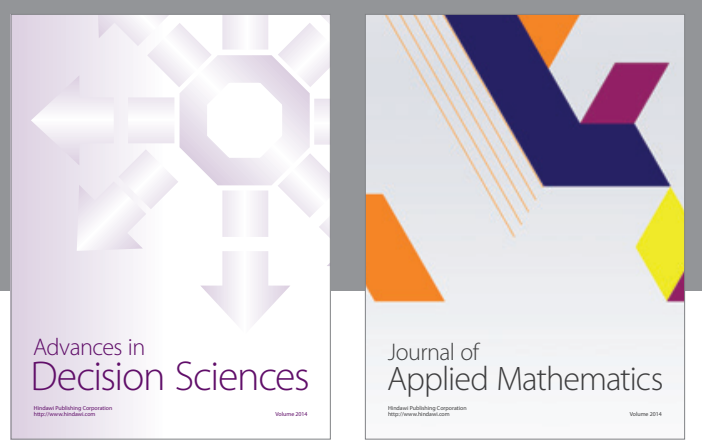

Algebra

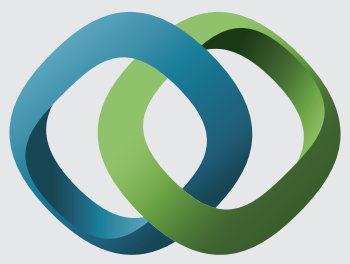

\section{Hindawi}

Submit your manuscripts at

http://www.hindawi.com
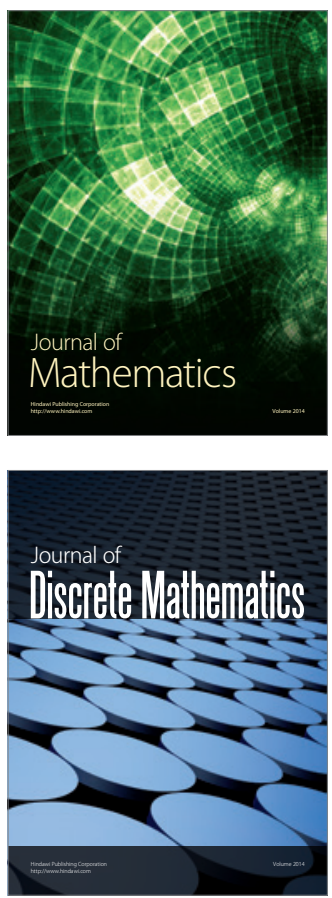

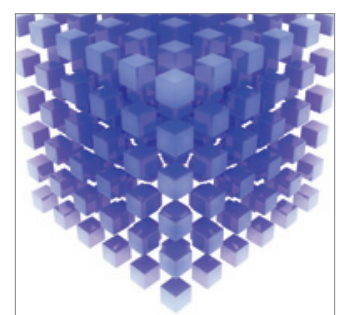

Mathematical Problems in Engineering
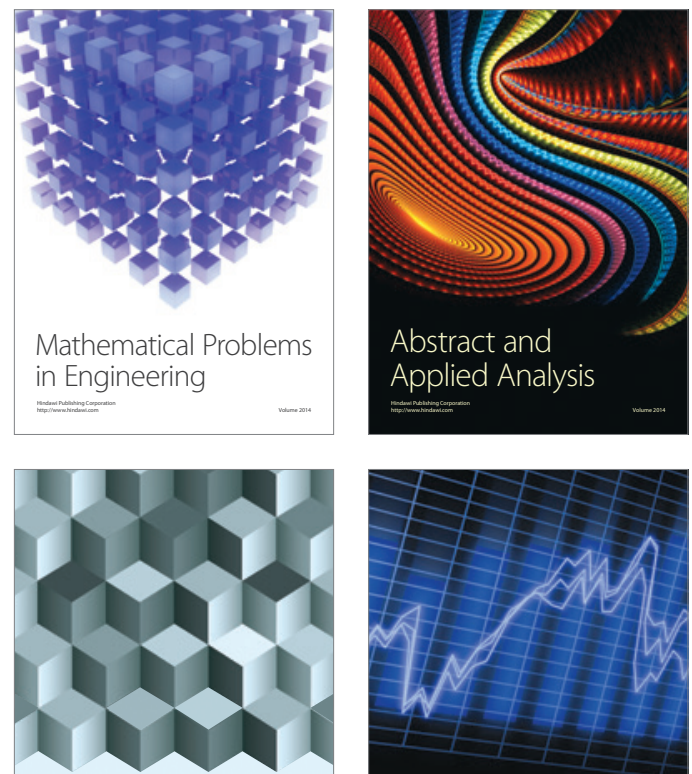

Journal of

Function Spaces

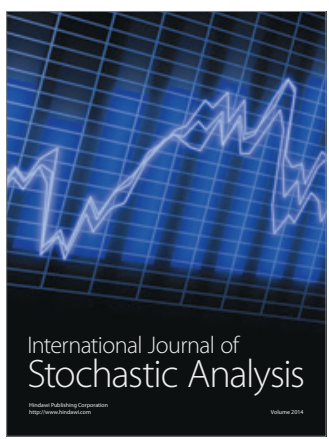

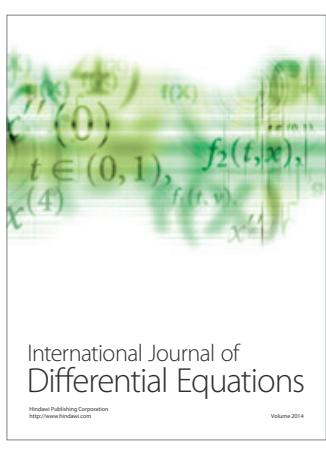
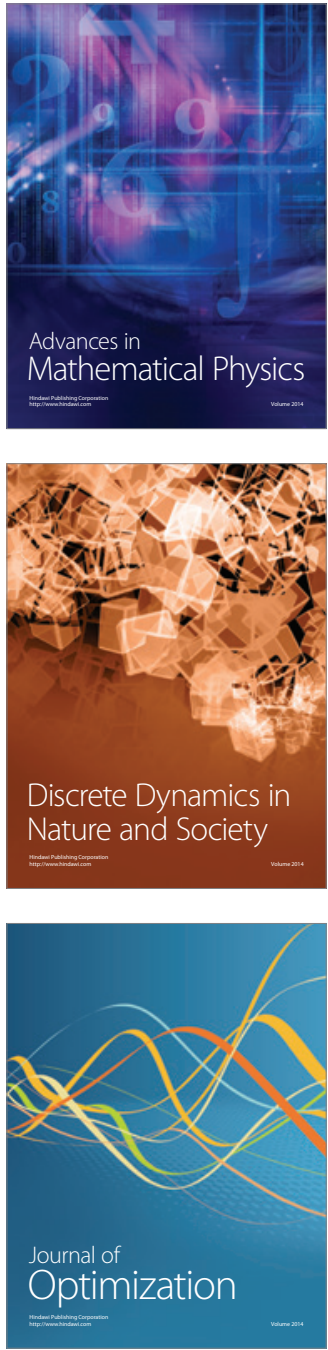